\title{
Core Abilities Evaluation Index System Exploration and Empirical Study on Distributed PV-Generation Projects
}

\author{
Lin $\mathrm{He}^{1}{ }^{1}$, Chang-Ling $\mathrm{Li}^{1}$, Qing-Yun Nie ${ }^{2}$, Yan Men ${ }^{1}$, Hai Shao ${ }^{1}$ and Jiang Zhu ${ }^{3, *}$ \\ 1 Economy and Technology Research Institute, State Grid Xinjiang Electric Power Corporation, \\ Wulumuqi 830011, China; hbdlljp@163.com (L.H.); paperxjl@163.com (C.-L.L.); \\ ljp@ncepu.edu.cn (Y.M.); shaohaixj@126.com (H.S.) \\ 2 School of Economics and Management, North China Electric Power University, Beijing 102206, China; \\ nqyncepu@ncepu.edu.cn \\ 3 Strategic and Economic Research Department, State Power Investment Corporation Research Institute, \\ Beijing 102209, China \\ * Correspondence: zhujiang1125@126.com; Tel.: +86-010-5668-1929
}

Received: 7 October 2017; Accepted: 4 December 2017; Published: 7 December 2017

\begin{abstract}
In line with the constraints of environmental problems and economic development, large-scale renewable-generation projects have been planned and constructed in recent years. In order to achieve sustainable power development and improve the power supply structure, China's government has focused on distributed photovoltaic (PV) generation projects due to their advantages of clean emission and local consumption. However, their unstable output power still brings a series of problems concerning reliability, investment income, and available substitution proportion to traditional power, and so on. Therefore, it is imperative to understand the competitive development abilities of distributed PV generation projects and measure them effectively. First, through various investigation methods such as literature reviews, feasibility report analysis and expert interviews, the factors that influence the core abilities of distributed PV-generation projects were explored based on the micro-grid structure. Then, with the indexed exploration results, the factors were classified into 6 dimensions, i.e., investment and earning ability, production and operation ability, power-grid coordination ability, energy-conservation and emission-reduction ability, sustainable development ability, and society-serving ability. Meanwhile, an evaluation index system for core abilities of distributed PV-generation project was constructed using all quantitative indicators. Third, for examining the availability of the evaluation index system, combination weighting and techniques for order preference by similarity to an ideal solution (TOPSIS) methods were adopted to assess the practical distributed PV-generation projects. The case study results showed that installed capacity, local economy development, and grid-connected power quantity will influence the core abilities of distributed PV-generation project, obviously. The conclusions of the evaluation analysis on core abilities can provide useful references to operate and manage distributed PV-generation projects and promote their sustainable and health advantages. The proposed evaluation index system can also be used to assess power-generation projects in other types of energy, such as wind power and hydropower.
\end{abstract}

Keywords: core abilities; distributed photovoltaic (PV)-generation project; comprehensive evaluation; combination weighting; techniques for order preference by similarity to an ideal solution (TOPSIS)

\section{Introduction}

In order to realize green development, flexible scheduling and the low-carbon transition of electric power, more renewable power started to be exploited and utilized in China following the 
new-round power market reform in 2015. Meanwhile, through the promotion of the electric power development plan in the 13th five-year period, the installed capacity and consumption ratio of renewable energy will increase rapidly. By the end of 2016, the total power generation in China reached $614.25 \mathrm{GWh}$, an increase of 5.6\% compared with the level in 2015 [1]. In the power supply structure, renewable energies, such as hydropower, wind power and solar power, accounted for $24.3 \%$ of total power generation. Among numerous power-generation types, distributed generation using renewable and clean energy has developed rapidly in recent years. Due to its advantages of being environmentally-friendly and easily consumed, there has been a focus on the distributed photovoltaic (PV) generation project which has been generalized widely. With data from National Energy Administration, China's distributed PV-generation capacity had a newly installed 34.54 GW in 2016, which shows its huge development potential [2]. However, China's distributed PV-generation industry is still in its infancy, so it is important to identify its real core ability in this complex generation environment in order to realize its sustainable development.

From the competitiveness perspective in previous studies, the core ability of a generation project usually contains aspects of technology, cost and environmental effects [3-5]. However, their assessment have not been comprehensive and cannot meet the multi-objective development requirements of distributed energy at present. With this widely accepted viewpoint, the influences of distributed power-generation projects on the power grid and other generation types have been taken into account in recent studies [6]. In terms of basic concepts, attention to the core ability of distributed power generation has changed from reliability to flexibility [7-9]. More comprehensive benefits from distributed power generation have been focused on. Thus, the core ability of distributed generation projects needs to be refined and extended to multiple dimensions. In this paper, the core ability of distributed PV-generation project was defined as a comprehensive ability aiming at the goals of its economic operation, grid coordination, energy substitution, energy saving, emission reduction and demand satisfaction in a complex electric system. These abilities will be examined to help in the assessment of a distributed PV project's actual development level and provide optimal references for its sustainable development. It is imperative to construct the evaluation index system for the core abilities of distributed PV-generation projects systematically and find an effective evaluation method to examine practical projects scientifically, and this is the paper's most important contribution.

Therefore, this study focuses on the evaluation of core abilities of distributed PV-generation projects. Based on the literature, feasibility reports and expert interviews, the evaluation indexes for core abilities of distributed PV-generation projects will be explored deeply. Then, by using combination weighting and techniques for order preference by similarity to an ideal solution (TOPSIS) evaluation methods, an evaluation model will be constructed scientifically and systematically. Finally, three experimental projects will test the effectiveness of the core abilities evaluation index and method. This exercise can provide management references for both the industry and enterprises. The model adopted in this paper can also provide an effective tool for assessing a distributed PV-generation project or other renewable generation projects. The comprehensive evaluation on distributed PV-generation projects will help government and enterprise managers to understand their core development abilities and plan their development paths more thoughtfully.

\section{Methodology}

In order to determine influencing factors and build the evaluation system for the core abilities of distributed PV-generation projects, the micro-grid structure, related literature, and feasibility reports will be analyzed to form a preliminary list of indexes influential to the core abilities of distributed PV-generation project. Finally, combined with expert interviews, important indexes will be selected from different evaluation dimensions. The research process of this paper is shown in Figure 1.

First, based on the micro-grid structure, the factors influential to the core abilities of distributed PV-generation projects were analyzed broadly. Combining this with the literature research results and project evaluation content in feasibility reports, the indexes were initially selected. Then, with the 
experts' experience, the evaluation index system was constructed for the core abilities of distributed PV-generation projects. Meanwhile, the evaluation model for core abilities was built by using combination weighting and techniques for order preference by similarity to ideal solution (TOPSIS) evaluation methods. Finally, with the index system and evaluation model, the experimental projects were assessed comparatively to examine the availability of the index system and the evaluation method.

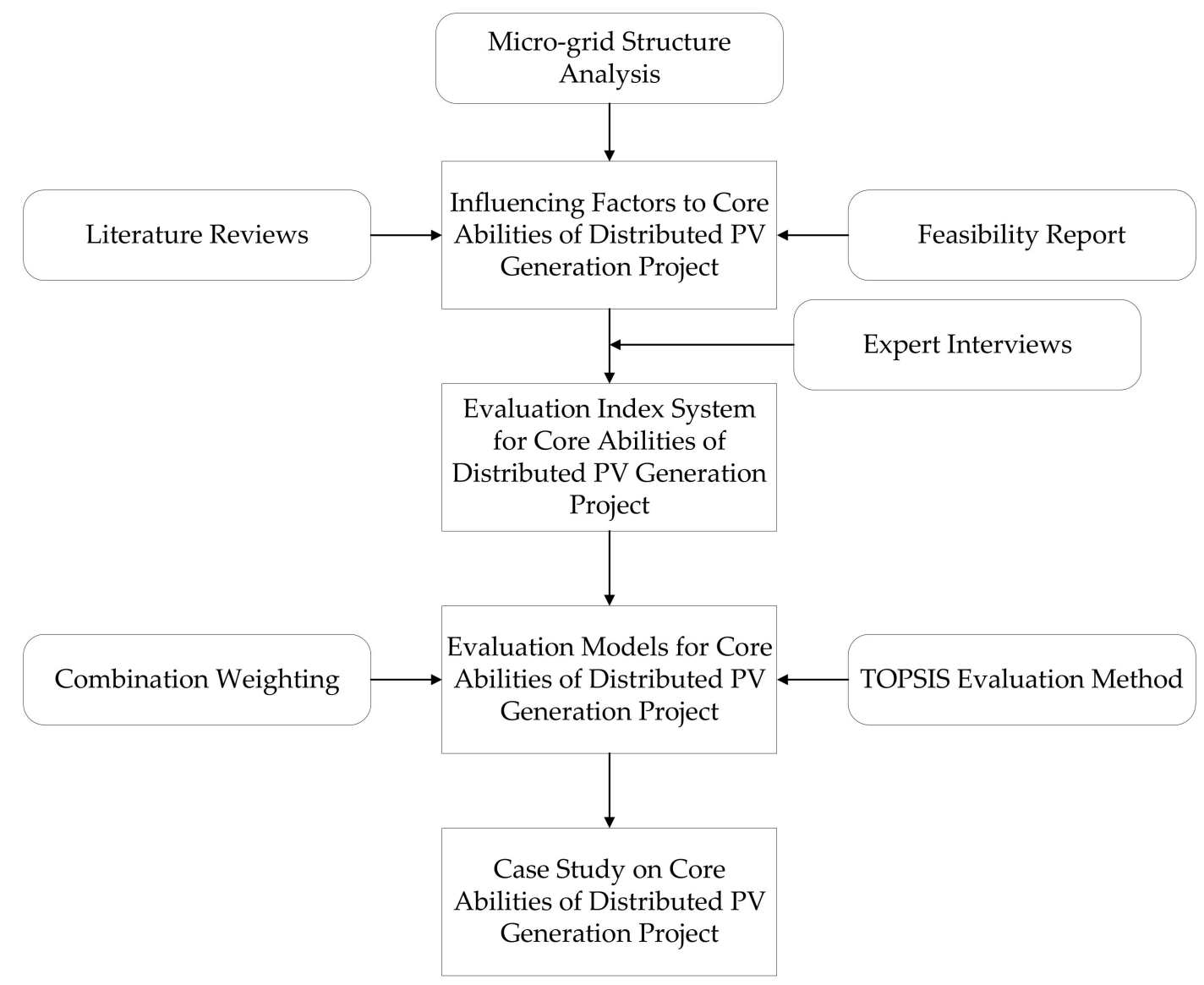

Figure 1. The research process for the core abilities of distributed PV-generation projects.

\subsection{Micro-Grid Structure Analysis}

From the perspective of production and operation, the main participants in a micro-grid include the generation system, storage system, power grid and power consumers (shown in Figure 2). In this complex system, different participants have different roles. For instance, the distributed generation systems provide power energies to the consumers and the power gird. The storage system is used to reserve excess power and supplement the load gap for the power grid. The power grid needs to balance the output of different generation systems. Therefore, understanding the relationships between different participants in a micro-grid is helpful for identifying the role of a distributed PV generation system. In the micro-grid system, the distributed PV-generation system should guarantee the generation output at a certain level in order, first, to achieve a financial benefit. Meanwhile, the generation output of the distributed PV-generation system should satisfy power-grid scheduling and the demand of local power consumers. Additionally, the storage system and other factors also influence the core abilities of distributed PV-generation projects. The specific indexes will be explored via literature reviews, feasibility report analysis and expert interviews as follows. 


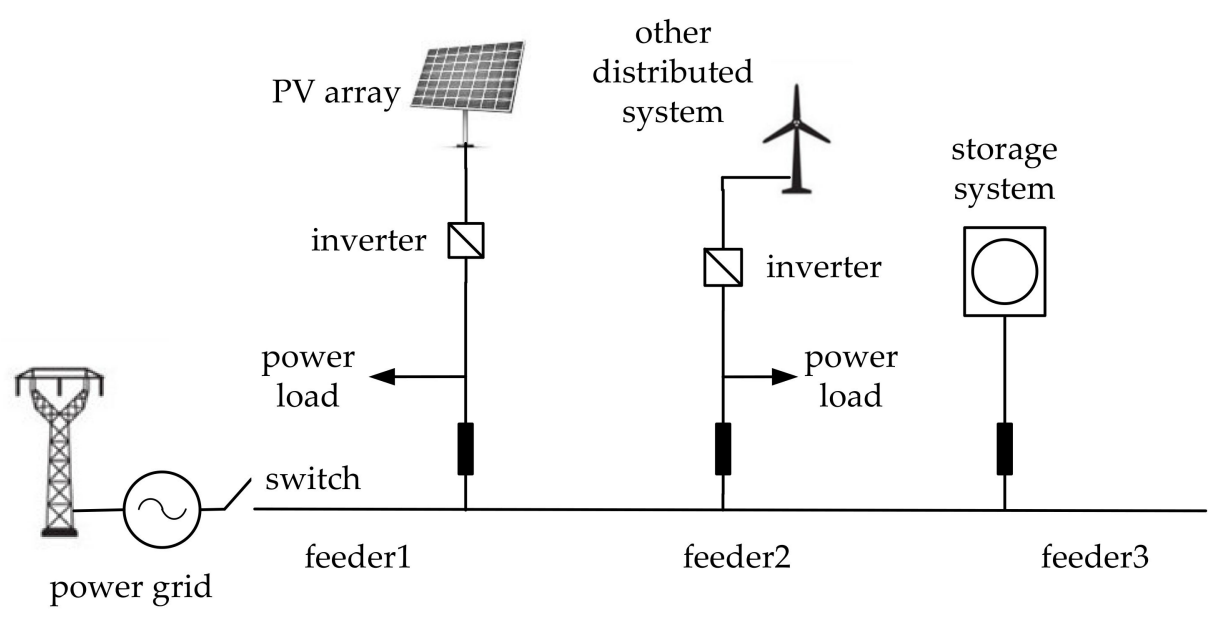

Figure 2. Micro-grid structure with distributed power-generation systems.

\subsection{Literature Reviews}

Based on previous research results, most evaluations of PV-generation projects or other renewable-generation projects have been taken into account resources, geography, technology, production, economy, environment, society and other aspects. In particular, solar resources were assessed through various techniques, such as geographic information, satellite estimation and ground-station measurements. The PV-generation potential, impact on the climate and generation efficiency caused by geographic factors were widely taken into the resource evaluations [10-13]. From the angle of the PV development trend around the world, the PV-generation resources, technologies, policies and environmental influences were summarized comprehensively [14-17]. Especially in the case of real-life PV projects, the techno-economic and whole life-cycle evaluation methods were adopted in order to assess economic performance [18-21]. Economic assessment results can provide key indexes for the core abilities evaluation of distributed PV-generation projects. Meanwhile, the climate or environmental effects caused by PV project diffusion were also studied deeply [22-26]. PV generation costs and emissions are the topics of most concern. In addition, other researchers and experts have also explored and assessed PV projects from the grid, storage and consumption sides [27-32]. The coordination development relations of multiple participants have mainly been considered and evaluated when PV projects were connected to the power grid and storage system. The literature reviews show that many factors are related to the core abilities of distributed PV-generation projects. They need to be chosen according to the importance if core abilities by practical experience. As shown in Table 1, the index lists are selected from the literature which filters out an initial index range for core abilities evaluation of distributed PV-generation projects.

Table 1. Research summary for PV project evaluation.

\begin{tabular}{clc}
\hline Main Aspects & \multicolumn{1}{c}{ Specific Content } & Mentioned No. of Times \\
\hline Resources & $\begin{array}{l}\text { Rodrigo A. Escobar, et al. [10] and Mark Z. } \\
\text { Jacobson, et al. [15] found the solar energy resource has } \\
\text { an effect on PV generation. }\end{array}$ & 2 \\
\hline Geography & $\begin{array}{l}\text { Gang He and Daniel M. Kammen [13] also pointed it out } \\
\text { that the location will influence the PV project. }\end{array}$ & 1 \\
\hline Technology & $\begin{array}{l}\text { Ali H.A., et al. [14], Vivek Tomar [19] and } \\
\text { Sandip Ravi Kumar, et al. [28] showed that technical } \\
\text { factors may determine the PV development level, } \\
\text { such as grid-connection. }\end{array}$ \\
\hline
\end{tabular}


Table 1. Cont.

\begin{tabular}{|c|c|c|}
\hline Main Aspects & Specific Content & Mentioned No. of Times \\
\hline Production & $\begin{array}{l}\text { Yatindra K. Ramgolam, et al. [12], } \\
\text { Worrada Nookuea, et al. [21], Hong-Bo Duan, et al. [25], } \\
\text { Alessandro Franco, et al. [32] figured that the output } \\
\text { features are the basic drivers for PV power generation. }\end{array}$ & 4 \\
\hline Economy & $\begin{array}{l}\text { Most researchers considered that the business models } \\
\text { and financing and tariff mechanisms are the main factors } \\
\text { in economic evaluation of PV projects, such as Alex Park } \\
\text { and Petros Lappas [18], Mallory E. Flowers, et al. [22] } \\
\text { and so on. }\end{array}$ & 5 \\
\hline Environment & $\begin{array}{l}\text { Environmental effects of PV generation are another } \\
\text { important aspect in PV project evaluation proposed by } \\
\text { Dougal Burnett, et al. [11], and Weiwu Ma, et al. [24]. }\end{array}$ & 2 \\
\hline Policy & $\begin{array}{l}\text { Hongwei Wang, et al. [16] focused on policy influences } \\
\text { on PV. }\end{array}$ & 1 \\
\hline
\end{tabular}

\subsection{Feasibility Report Analysis}

In this paper, five feasibility reports of distributed PV-generation projects with different installed capacities were collected in order to identify the evaluation indexes from practical perspectives. By integrating the indexes from these feasibility reports, the main evaluation dimensions include generation resource, geological condition, project goal and construction scale, electrical design, civil-engineering design, fire control, organization and management, environmental protection, and financial and social assessment. Given different construction characteristics, some feasibility reports of distributed PV-generation projects also take other indexes into account, such as the local economy development level and social contribution. The quantitative indexes used in feasibility reports provide important references to select and build the evaluation system for core abilities of distributed PV-generation projects in this paper. The indexes summarized from the feasibility reports are shown in Table 2.

Table 2. Evaluation index summary on feasibility reports of distributed PV-generation projects.

\begin{tabular}{ccccccc}
\hline Main Dimension & Report 1 & Report 2 & Report 3 & Report 4 & Report 5 & Total \\
\hline Generation resource & $\sqrt{ }$ & $\sqrt{ }$ & $\sqrt{ }$ & $\sqrt{ }$ & $\sqrt{ }$ & 5 \\
Geological condition & $\sqrt{ }$ & $\sqrt{ }$ & $\sqrt{ }$ & $\sqrt{ }$ & $\sqrt{ }$ & 5 \\
Organization & & $\sqrt{ }$ & $\sqrt{ }$ & $\sqrt{ }$ & $\sqrt{ }$ & 4 \\
Management process & & $\sqrt{ }$ & $\sqrt{ }$ & $\sqrt{ }$ & $\sqrt{ }$ & 4 \\
Electrical design & $\sqrt{ }$ & $\sqrt{ }$ & $\sqrt{ }$ & $\sqrt{ }$ & $\sqrt{ }$ & 5 \\
Financial assessment & $\sqrt{ }$ & $\sqrt{ }$ & $\sqrt{ }$ & $\sqrt{ }$ & $\sqrt{ }$ & 5 \\
Economic development & $\sqrt{ }$ & $\sqrt{ }$ & $\sqrt{ }$ & & & 3 \\
Society serving & $\sqrt{ }$ & & $\sqrt{ }$ & $\sqrt{ }$ & $\sqrt{ }$ & 4 \\
Environmental protection & $\sqrt{ }$ & $\sqrt{ }$ & $\sqrt{ }$ & $\sqrt{ }$ & $\sqrt{ }$ & 5 \\
\hline
\end{tabular}

Note: Feasibility reports were collected from different distributed PV-generation projects for different applications in different areas, such as a 6.27 MWp distributed PV project for coal mining (report 1), a 3.453 MWp rooftop PV project (report 2), a 15.723 MWp PV power supply project for a tourist area (report 3), a 1.6243 MWp residential project (report 4), and a 10.126 MWp PV system on a micro-grid (report 5).

\subsection{Expert Interviews}

Semi-structure interviews were undertaken with experts to solicit professional views about the core abilities of distributed PV-generation projects. With the collected index from literature reviews and feasibility reports, more rational and important factors were also chosen. In addition, the interviews also helped to group the indexes. In this study, 13 industry experts were interviewed from different specializations and companies, such as 3 PV module manufactures, 1 PV-generation technology 
researcher, 2 power industry investors, $4 \mathrm{PV}$ plant operators, 1 power-grid company and 2 consulting companies. In particular, they were Xiaoqun Zhang (production head) and $\mathrm{Li} \mathrm{Du}$ (senior engineer) from JinkoSolar Company (Shangrao, China); Jifan Gao (general manager) from TrinaSolar Company (Changzhou, China); Wentao Yu (technology R\&D engineer), Chao Meng (engineer) and Ning Bai (deputy head) from State Power Investment Corporation (Beijing, China); Xin Lu (senior engineer) and Yang Liu (senior engineer) from China Huaneng Group (Beijing, China); Shanshan Chen (engineer) and Baiyang Song (engineer) from Guohua Power Investment Corporation (Beijing, China)); Li He (deputy head) from State Power Grid Xinjiang Corporation (Wulumuqi, China); Heyun Dong (engineer) and Yisheng Yang (engineer) from Electric Power Planning and Engineering Institute (Beijing, China). All experts were research partners and have at least 5 years' working experience in the electric power industry.

According to the results of the expert interviews, the factors influential to the core abilities of distributed PV-generation project were clustered as shown in Figure 3. For example, the cost and benefit should be put in the first place in the process of core abilities' evaluation on the distributed PV-generation project. The traditional financial indexes were integrated into investment and earning ability. The technological parameters of distributed PV-generation projects were also an important dimension for assessing their core abilities which were classified into the index of production and operation abilities. Meanwhile, considering the projects' influences on the grid, environment, self-development and social development, the relative indexes were grouped into the dimensions of power-grid coordination ability, energy-conservation and emission-reduction ability, sustainable development ability, society-serving ability respectively. The factors on the aspects of geography and organization management were rejected by experts due to their low correlation and difficult quantization to core abilities of distributed PV-generation project. The specific indexes and their calculation methods will be introduced in the next section.

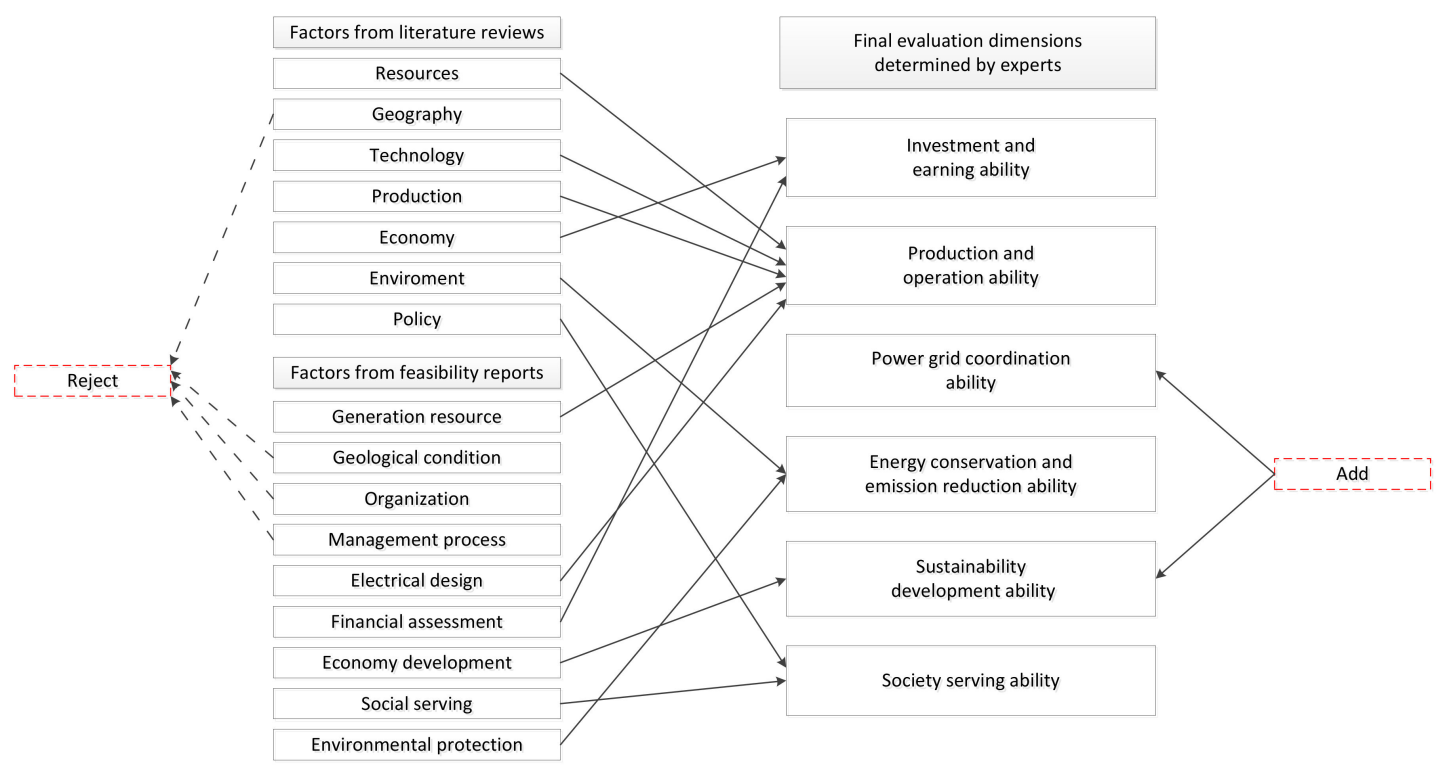

Figure 3. Evaluation indexes selection by experts.

\section{Evaluation Index System for Core Abilities of Distributed PV-Generation Projects}

In order to make the evaluation results more objective and accurate, all indexes in this research were measured using quantitative methods. With the research results in Section 2, the core abilities of distributed PV-generation projects can be assessed from 6 dimensions, i.e., investment and earning ability, production and operation ability, power-grid coordination ability, energy-conservation and emission-reduction ability, sustainable development ability, society-serving ability. The indexes in 
different dimensions and their calculation methods are as follows, relying on the constructed evaluation index system in Figure 4.

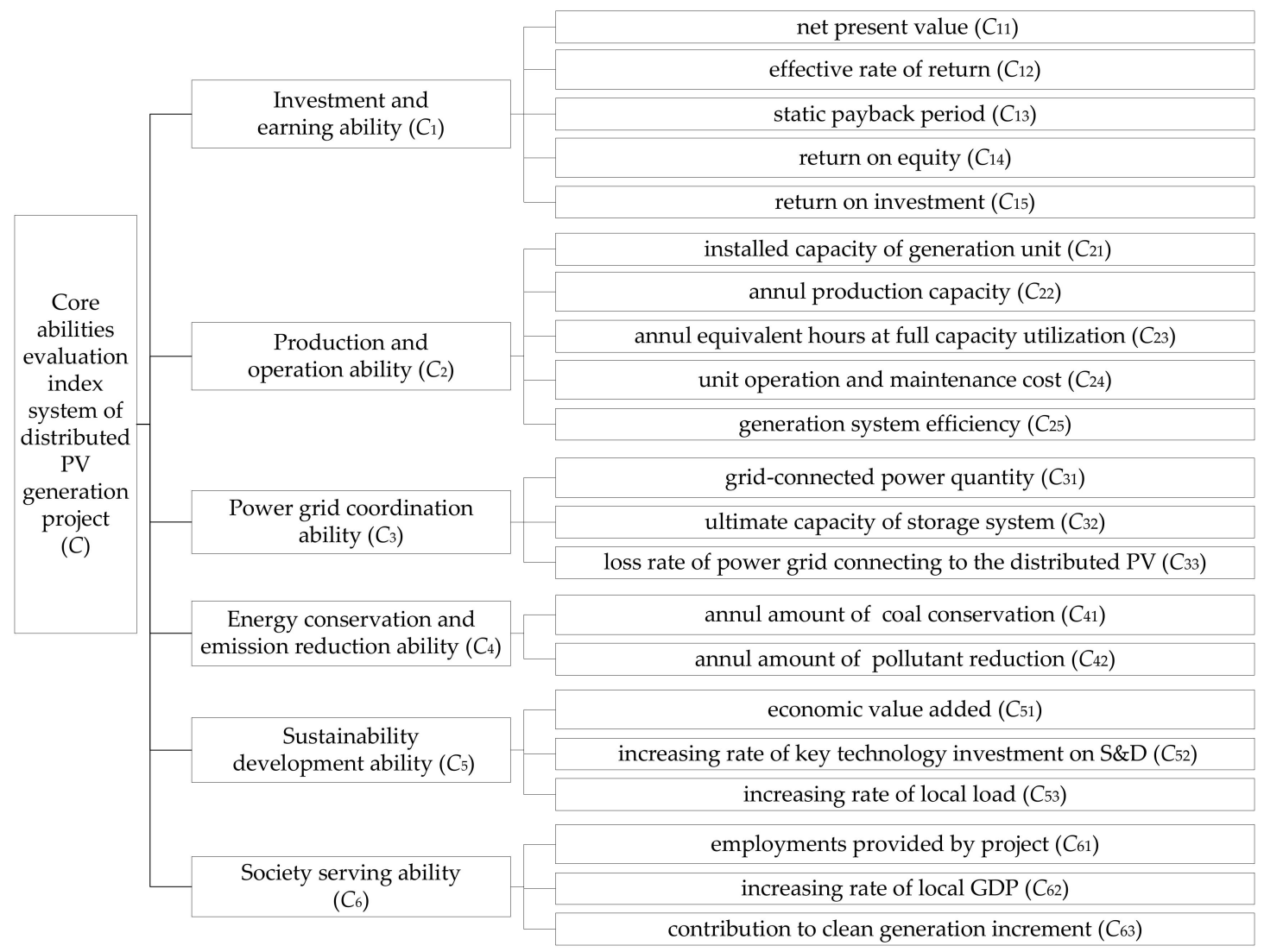

Figure 4. Evaluation index system for core abilities of distributed PV-generation project.

\subsection{Investment and Earning Ability}

The index is set to explore the benefit-earning ability via traditional financial and techno-economic indicators, such as net present value (NPV), internal rate of return (IRR), static payback period $(T)$, return on equity $(R O E)$ and return on investment $(R O I)$. The calculation of each indicator is shown as follows.

(1) Net present value (NPV). NPV is a basic economic indicator to describe the project's profit during the construction and operation period. It is the sum of differentials between cash inflows and outflows in every year. It can be calculated by Equation (1).

$$
N P V=\sum_{t=0}^{n}\left[(C I-C O)_{t} \times\left(1+i_{0}\right)^{-t}\right]
$$

In Equation (1), CI stands for the annual cash inflow; $C O$ is the annual cash outflow; $t$ represents the construction and operation period and $i_{0}$ is the basic discount rate.

(2) Effective rate of return. Compared with internal rate of return (IRR), the rationality of the effective rate of return can be determined. When effective rate of return is bigger than internal rate of return, this means the effective rate of return is acceptable and valuable. IRR can be calculated by Equation (2).

$$
N P V=\sum_{t=0}^{n}\left[(C I-C O)_{t} \times(1+I R R)^{-t}\right]=0
$$


In Equation (2), IRR is the rate of return which makes the net cash flows zero. IRR can be also named as expected rate of return. As it is greater than IRR, NPV is better.

(3) Static payback period $(T)$. $T$ stands for the return ability of investment. If $T$ is smaller, the ability is better. A static payback period can be calculated via Equation (3).

$$
T=t_{\left(\sum(C I-C O)>0\right)}-1+\frac{|C I-C O|_{t-1}}{(C I-C O)_{t}}
$$

In Equation (3), $t_{\left(\sum(\mathrm{CI}-\mathrm{CO})>0\right)}$ stands for the year $t$ when the accumulative net flows are more than 0 for the first time. $|C I-C O|_{t-1}$ is the absolute value of net cash flow in the year $t-1$, and $(C I-C O)_{t}$ is the net cash flow in the year $t$. In general, $T$ should be shorter than the $T_{0}$ calculated by basic discount rate $i_{0}$.

(4) Return on equity (ROE). ROE stands for the earning ability of equity. It can be measured through Equation (4).

$$
R O E=\frac{N P}{A N W} \times 100 \%
$$

where NP stands for net profits, $A N W$ is the average net worth.

(5) Return on investment (ROI). ROI equals pre-tax profits divided by total investment. The calculation method is shown in Equation (5).

$$
R O I=\frac{P P}{T I} \times 100 \%
$$

where $P P$ stands for pre-tax profit, $T I$ is the total investment.

\subsection{Production and Operation Ability}

The production and operation ability of the core abilities of distributed PV-generation projects is mainly determined at a technical level. It contains the indicators of installed capacity of generation unit, annual production capacity, annual equivalent hours at capacity utilization, unit operation and maintenance cost, generation-system efficiency.

(1) Installed capacity of generation unit (IC). The data of installed capacity of a generation unit can be obtained from the production report directly.

(2) Annual production capacity $(A P C)$. Similar to $I C$, the data of annual production capacity can also be obtained from the production report directly.

(3) Annual equivalent hours at capacity utilization $(H)$. $H$ is used to check system production hours at full power level. It can be calculated via Equation (6).

$$
H=\frac{T G}{R C}
$$

where $T G$ stands for the unit total generation, and $R C$ stands for the rated capacity.

(4) Unit operation and maintenance cost (UC). UC is the significant expenditure in the production and operation process. It is a comprehensive indicator to reflect the production and operation ability of distributed PV-generation projects. It can be calculated via Equation (7).

$$
U C=\frac{A O M}{A P C}
$$

where $A O M$ is the annul operation and maintenance cost, and $A P C$ stands for the annual production capacity. 
(5) Generation system efficiency $(E)$. E reflects the resource utilization efficiency of the generation unit through energy input and output. The measurement is shown in Equation (8).

$$
E=\frac{U E O}{R E I} \times 100 \%
$$

where $U E O$ is the unit energy output, and REI stands for the resource energy input.

\subsection{Power-Grid Coordination Ability}

The power-grid coordination ability is used to assess the coordination production ability between a distributed PV-generation project and power grid. It includes the grid-connected power quantity, ultimate capacity of the storage system, and loss rate of the power grid connecting to the distributed PV.

(1) Grid-connected power quantity (GPP). GPP shows the acceptable ability of the power grid to distribute PV power. It will have critical effects on distributed PV generation. The data can be obtained from the statistics of both distributed PV operators and power grid companies.

(2) Ultimate capacity of storage system. This indicator is determined by the design capacity of the storage system. It should consider both the technical and economic factors of distributed power production.

(3) Loss rate of power grid connecting to the distributed PV power. When distributed PV power is connected to the local power grid, it will influence the stability and power scheduling of the grid, especially the loss rate of the grid in transmission and distribution. So the loss rate can examine the distributed PV-generation project's relationship with a local power grid. The data can be adopted from the statistics of the grid company.

\subsection{Energy Conservation and Emission-Reduction Ability}

The biggest advantage of distributed PV-generation projects are their environmental benefits. Therefore, the energy-conservation and emission-reduction ability is set to measure coal conservation and pollutant reduction.

(1) Annual amount of coal conservation. Due to renewable and clean energy input, the production of a distributed PV-generation project can save coal consumption. It is a basic indicator of the energy=conservation ability of distributed PV-generation projects. It can be measured through generation amount.

(2) Annual amount of pollutant reduction. Thermal power generations discharge $\mathrm{CO}_{2}, \mathrm{SO}_{X}, \mathrm{NO}_{X}$, smoke, dust and ash which are serious problems for the local environment. The substitution of a distributed PV-generation project for a thermal power plant can solve the pollution and emission problems effectively.

\subsection{Sustainable Development Ability}

The sustainable development ability aims to evaluate whether the distributed PV-generation project has sustainable development potential. This index is assessed from the aspects of economy, technology and consumption.

(1) Economic value added (EVA). EVA is a common indicator for examining an enterprise's financial benefit used widely in the evaluation of power-generation projects. EVA is also the basis and core of a value-management system. For the distributed PV-generation project, adopting EVA can help managers to understand its sustainable development ability well. It can be assessed via Equation (9).

$$
E V A=N P A T-C C
$$

where NPTA stands for the net profit after tax, CC is the capital cost of a distributed PV-generation project. 
(2) Increasing rate of key technology investment on sustainability and development (S\&D) (TIR). TIR is set to reflect the technology S\&D investment of the distributed PV-generation project and its operators. It is a relative value, as shown in Equation (10).

$$
T I R_{t}=\frac{t i_{t}-t i_{t-1}}{t i_{t-1}}
$$

In Equation (10), $t i$ stands for the annual technology investment.

(3) Increasing rate of local load (LIR). LIR can reflect the development potential of distributed generation power. The faster the local load increases, the more generation space the distributed PV-generation project has. It can be calculated via Equation (11).

$$
\operatorname{LIR}_{t}=\frac{l_{t}-l_{t-1}}{l_{t-1}}
$$

In Equation (11), $l$ stands for the annual local load.

\subsection{Society-Serving Ability}

As a project serving the public, the core abilities of a distributed PV-generation project should contain the society-serving ability. It can be evaluated from the indicators of employment, increasing rate of local GDP and contributions to the clean-generation increment.

(1) Employment provided by the project. Employment provided by the project is a direct indicator to show the society-serving ability of distributed PV-generation projects.

(2) Increasing rate of local GDP (GIR). If the local GDP grows fast, power demand must be large to support economic development. Thus, from the increasing GDP rate, an increasing potential of distributed PV-generation can be seen easily. The GIR can be calculated via Equation (12).

$$
G I R_{t}=\frac{G D P_{t}-G D P_{t-1}}{G D P_{t-1}}
$$

(3) Contributions to clean-generation increment (CCGI). In order to optimize the energy structure, renewable and clean energy is widely used in power generation. For testing the generation contributions of distributed PV projects, CCGI is used to assess the increment ratio of renewable generation produced by distributed PV projects. The calculation of CCGI is shown in Equation (13).

$$
C C G I_{t}=\frac{P V_{t}}{C E G_{t}-C E G_{t-1}}
$$

where $P V_{t}$ stands for the $P V$ project generation in year $t$, and CGE is the total generation of clean energy in this power supply area.

\section{Evaluation Models for Distributed PV Project}

\subsection{Combination Weighting Method}

After several years' improvement, the weighting methods used in evaluation such as set-valued iteration, entropy methods and so on, have matured [33,34]. These different methods have their own characteristics; for example, set-valued iteration weightings of the indexes rely on the experts' experience, but the entropy method just determines the weights of index information. The absolute qualitative or absolute quantitative methods cannot measure the index weights properly. Therefore, combinations of methods have developed rapidly in recent years. With qualitative and the quantitative weighting results, the technique of combination weighting can fix these two methods effectively in order to make a comprehensive weighting decision [35]. Taking set-valued iteration method and entropy method as examples, the combination weighting process is shown as follows. 
(1) Assuming that there are $n$ indexes in the evaluation system, the weighting results of the set-valued iteration method and entropy methods are set as $T=\left\{t_{1}, t_{2}, \ldots, t_{n}\right\}$ and $S=\left\{s_{1}, s_{2}, \ldots, s_{n}\right\}$ respectively. The set of combination weighting results is $W=\left\{w_{1}, w_{2}, \ldots, w_{n}\right\}$.

(2) If the relative importance degree of $T$ to $W$ is $\alpha$, and the relative importance degree of $S$ to $W$ is $\beta$, the objective function of $\mathrm{W}$ can be described as Equation (14).

$$
\min H\left(w_{j}\right)=\alpha \times\left(w_{j}-t_{j}\right)^{2}+\beta \times\left(w_{j}-s_{j}\right)^{2}
$$

In Equation (14), $\sum w_{j}=1$ and $1 \leq j \leq n$. In this model, the expected values of $T$ and $S$ are their actual weighting values, i.e., $t_{j}$ and $s_{j}$. Then, the relative importance degree of each index can be measured according to Equation (15).

$$
\left\{\begin{aligned}
\alpha_{j} & =\frac{t_{j}}{t_{j}+s_{j}} \\
\beta_{j} & =\frac{s_{j}}{t_{j}+s_{j}}
\end{aligned}\right.
$$

The relative importance degree of $\alpha$ and $\beta$ can also be calculated via Equation (16).

$$
\alpha=\frac{\sum_{j=1}^{n} a_{j}}{\sum_{j=1}^{n} a_{j}+\sum_{j=1}^{n} \beta_{j}}=\frac{\sum_{j=1}^{n} a_{j}}{n}, \beta=\frac{\sum_{j=1}^{n} \beta_{j}}{\sum_{j=1}^{n} a_{j}+\sum_{j=1}^{n} \beta_{j}}=\frac{\sum_{j=1}^{n} \beta_{j}}{n}
$$

For each evaluation index $x_{j}$, take $H\left(w_{j}\right)$ as the minimum value, and hence Equation (15) can be transformed to Equation (17).

$$
\left\{\begin{array}{c}
\min H=\left\{H\left(w_{1}\right), H\left(w_{2}\right), \ldots, H\left(w_{n}\right)\right\} \\
\text { s.t. } \sum_{j=1}^{n} w_{j}=1,0 \leq w_{j} \leq 1,1 \leq j \leq n
\end{array}\right.
$$

Based on Equation (17), the combination weighting results can be determined using the results of the qualitative and quantitative methods. The multi-objective model can also be explored as a single objective function in Equation (18).

$$
\left\{\begin{array}{c}
\min H=\sum_{j=1}^{n}\left[a \times\left(w_{j}-t_{j}\right)^{2}\right]+\sum_{j=1}^{n}\left[\beta \times\left(w_{j}-s_{j}\right)^{2}\right] \\
\text { s.t. } \sum_{j=1}^{n} w_{j}=1,0 \leq w_{j} \leq 1,1 \leq j \leq n
\end{array}\right.
$$

\subsection{Technique for Order Preference by Similarity to an Ideal Solution (TOPSIS) Evaluation Method}

In this paper, all evaluation indexes are quantitative. In order to keep the data information optimal, a technique for order preference by similarity to an ideal solution (TOPSIS) is chosen to evaluate the core abilities of a distributed PV generation project due to its methodological advantages [36]. The steps of the TOPSIS evaluation model are introduced as follows.

(1) Matrix construction of multi-objective decision (R). Assume that $C=\left\{C_{1}, C_{2}, \ldots, C_{m}\right\}$ is the solution set of objective problems and $X=\left\{x_{1}, x_{2}, \ldots, x_{n}\right\}$ is the index set, the evaluation value of $X$ to $C$ is $r_{i j}(i=1,2, \ldots, m ; j=1,2, \ldots, n)$. Then, the matrix $R$ can be represented as Equation (19).

$$
R=\left(\begin{array}{cccc}
r_{11} & r_{12} & \ldots & r_{1 m} \\
r_{21} & r_{21} & \ldots & r_{2 m} \\
\ldots & \ldots & \ldots & \ldots \\
r_{n 1} & r_{n 2} & \ldots & r_{n m}
\end{array}\right)
$$


(2) Positive and negative ideal point setting. Combining this with the weighting result $W$, the decision matrix $Z=\left(z_{i j}\right)_{m \times n}$ can be calculated with $R$. From the decision matrix, the positive and negative ideal points can be set as $Z^{+}=\left(z_{1}{ }^{+}, z_{2}{ }^{+}, \ldots, z_{m}{ }^{+}\right)$and $Z^{-}=\left(z_{1}{ }^{-}, z_{2}{ }^{-}, \ldots, z_{m}{ }^{-}\right)$which can be measured via Equation (20).

$$
\left\{\begin{array}{l}
z_{i}^{+}=\max \left(z_{i 1}{ }^{+}, z_{i 2}{ }^{+}, \ldots, z_{i m}{ }^{+}\right) \\
z_{i}^{-}=\min \left(z_{i 1}{ }^{-}, z_{i 2}{ }^{-}, \ldots, z_{i m}{ }^{-}\right)
\end{array}\right.
$$

(3) Distance calculation of solution to ideal point. Set $D_{j}^{+}$and $D_{j}^{-}$as positive ideal point and negative ideal point respectively, the calculation method is shown in Equation (21).

$$
\left\{\begin{aligned}
D_{j}^{+} & =\sqrt{\sum_{i=1}^{m}\left(z_{i j}-z_{i}\right)^{2}} \\
D_{j}^{-} & =\sqrt{\sum_{i=1}^{m}\left(z_{i j}-z_{i}^{-}\right)^{2}}, i=1,2, \ldots, m ; j=1,2, \ldots, n
\end{aligned}\right.
$$

(4) Evaluation result ranking. According to the evaluation results, the solutions can be ranked by their distances to the negative ideal point. The solution values can be calculated via Equation (22).

$$
C_{j}=\frac{D_{j}^{-}}{D_{j}^{-}+D_{j}^{+}}, j=1,2, \ldots, n
$$

\section{Case Study}

\subsection{Project Selection}

In this paper, three practical distributed PV-generation projects were selected to analyze and evaluate core abilities. Their brief introductions are as follows.

(1) Project A. Distributed PV-generation project A is constructed for a coalfield in north-western China. Its construction capacity is $6.27 \mathrm{MWp}$, which consists of 6 generation units. The project is nearby a $35 \mathrm{kV}$ substation in the coalfield area. The generation from this distributed PV-generation project is all used by the coalfield. The operation period is set as 20 years with $171.61 \mathrm{GWh}$ total generation amounts. The annul generation is $8.58 \mathrm{GWh}$. The annual equivalent generation hours are 1368.08. Total investments are 47.75 million yuan.

(2) Project B. Distributed PV-generation project B is located in a tourist area in northern China. This project is near a $35 \mathrm{kV}$ substation and consists of 36,237 PV components. All generation power is consumed by the tourist area, which will work for 25 years. The total generation amounts are $459.23 \mathrm{GWh}$. The annual generations is $18.35 \mathrm{GWh}$. The annual equivalent generation hours are 2362.31. Total investment is 128.1 million yuan.

(3) Project C. Distributed PV-generation project $C$ is a residential project with construction capacity of 1.6243 MWp in eastern China. 7062 PV generation components are installed on the roof. The generation system is directly connected to a $10 \mathrm{kV}$ electrical circuit in the consumer side. In the 25-year operation period, its total generation amount is $60.88 \mathrm{GWh}$. The annual generation is $2.43 \mathrm{GWh}$. The annual equivalent generation hours are 1123.85. The total investment is 32.83 million yuan.

\subsection{Weighting Result Analysis}

According to Equations (13)-(17), the weighting results of the set-valued iteration method, entropy method and combination weighting method are shown in Figure 4. 
Figure 5 shows that the combination weighting method has adjusted the index weights effectively compared with the results in the set-valued iteration and entropy methods. By the combination weighting method, the weighting results are smoother and more comprehensive. Its average modified values to the set-valued iteration and entropy results are 0.3644 and 0.1497 , respectively. This proves that the combination weighting results are closer to the quantitative entropy method and avoid the qualitative errors of set-valued iteration caused by subjective factors. The combination weighting results are shown as follows.

$$
\begin{aligned}
& W=(0.0437,0.0356,0.0351,0.0389,0.0333,0.0377,0.0400, \\
& 0.0420,0.0491,0.0492,0.0408,0.0378,0.0422,0.0450, \\
& 0.0428,0.0354,0.0419,0.0366,0.0352,0.0428,0.0474)
\end{aligned}
$$

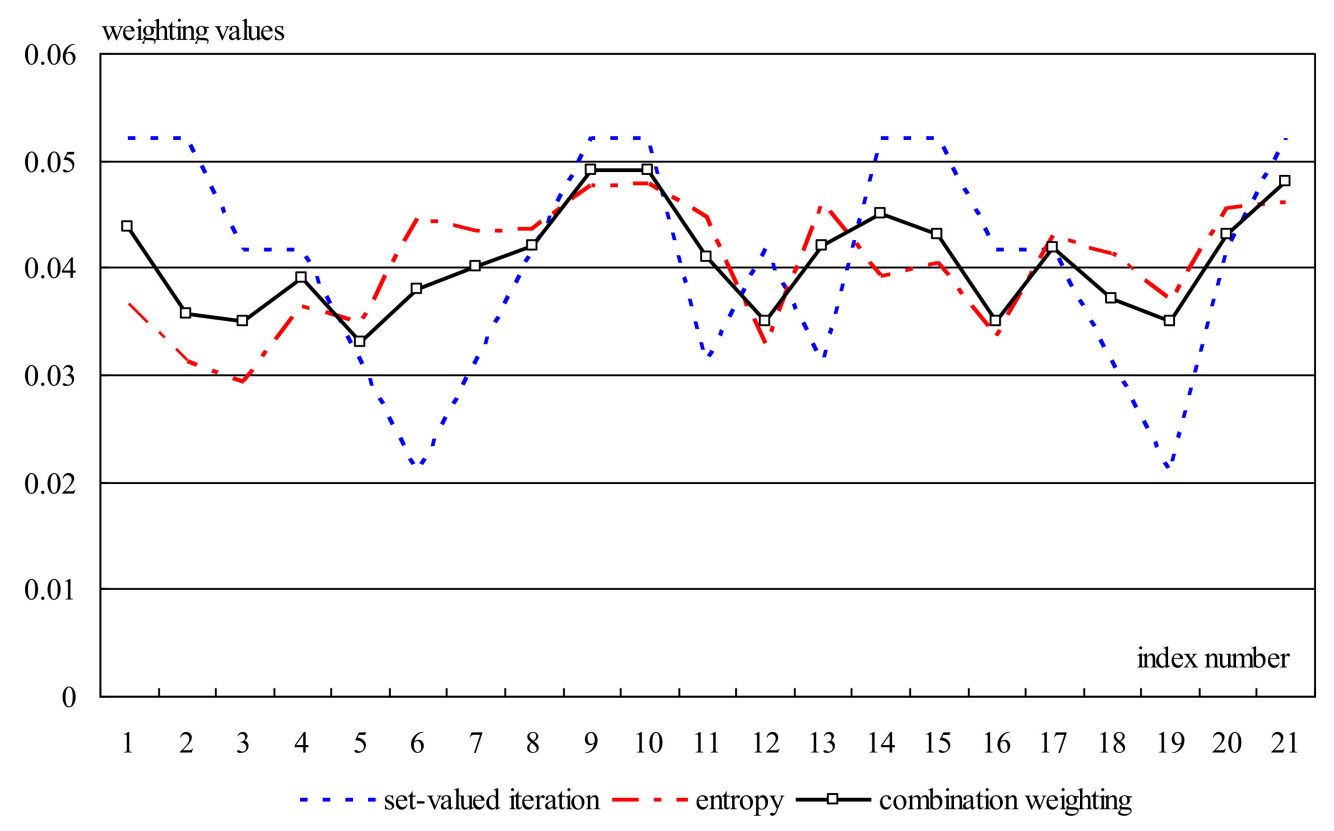

Figure 5. Weighting result comparison with different methods.

\subsection{Evaluation Result Analysis}

With the weighting results in Equation (22), the TOPSIS evaluation model can be used to assess the core abilities of these 3 distributed PV-generation projects. In Figure 6, the differentials of core abilities for each distributed PV project can be seen in every dimension.

(1) Investment and earning ability. Influenced by installed capacity, project B has the best performance in investment and earning ability. From the indicators of effective rate of return and static payback period, the abilities of project $\mathrm{A}$ are better than that in the other two projects. Project $C$ has an advantage in return on equity. The evaluation results of investment and earning ability in each project are $0.5317,0.8149$ and 0.0873 , respectively.

(2) Production and operation ability. From the evaluation conclusions, it can be found that the installed capacity with scale-production benefits has significant effects on production and operation ability. For example, the unit operation and maintenance cost of project B is just 0.018 yuan $/ \mathrm{kWh}$ due to its largest installed capacity in these three projects. Meanwhile, rich resources also influence production and operation ability. At project A in north-western China, rich solar energy promotes the efficiency of the generation system up to $87 \%$. The evaluation results of production and operation ability in projects A, B and C are $0.3398,0.8732$ and 0.1171 , respectively. 
(3) Power grid coordination ability. Based on the investigation in the feasibility report, power grid coordination ability is mainly determined by policy. In 2016, most of provinces in China developed a purchasing policy for renewable and clean generation power which improve the power supply structure. Due to its own electric power system, project A has better performance in terms of coordination ability on the aspects of grid-connected power quantity and loss rate of the power grid. Projects A, B and C's evaluation results for power grid coordination ability are $0.5782,0.3441$ and 0.0519 , respectively.

(4) Energy-conservation and emission-reduction ability. Similar to production and operation ability, project $B$ saves more coal and reduces more pollutant. The environmental effect on energy-conservation and emission-reduction in project $B$ is obvious. On the contrary, project $A$ and $C$ did not yet demonstrate their best environmental benefit. The evaluation results of energy conservation and emission reduction are $0.3645,0.9763$ and 0.0450 in projects $A, B$ and C, respectively.

(5) Sustainable development ability. Project A has the best evaluation result in EVA that can amount to 14.3 million yuan annually. Meanwhile, project A also shows its competitiveness on the increasing rate of local load. With greater acceptance of renewable power to the power grid, the ratio of renewable energy in the power supply structure has increased stably. Due to the technology improvement in micro-grids in particular, the potential of distributed generation projects has grown even further. The evaluation results of each project in the sustainable development ability are $0.3999,0.2123$ and 0.3833 .

(6) Society-serving ability. Project A provides more employments than projects B and C. On the aspect of increasing rate of local GDP, location $C$ has a better economic development environment which can promote the development of a distributed generation project. Project $\mathrm{B}$ generates more renewable energy for the local power supply increment. Therefore, the society-serving ability of project $B$ has the best evaluation result among these three projects. The evaluation results of the society-serving ability are $0.4066,0.4834$ and 0.3234 .

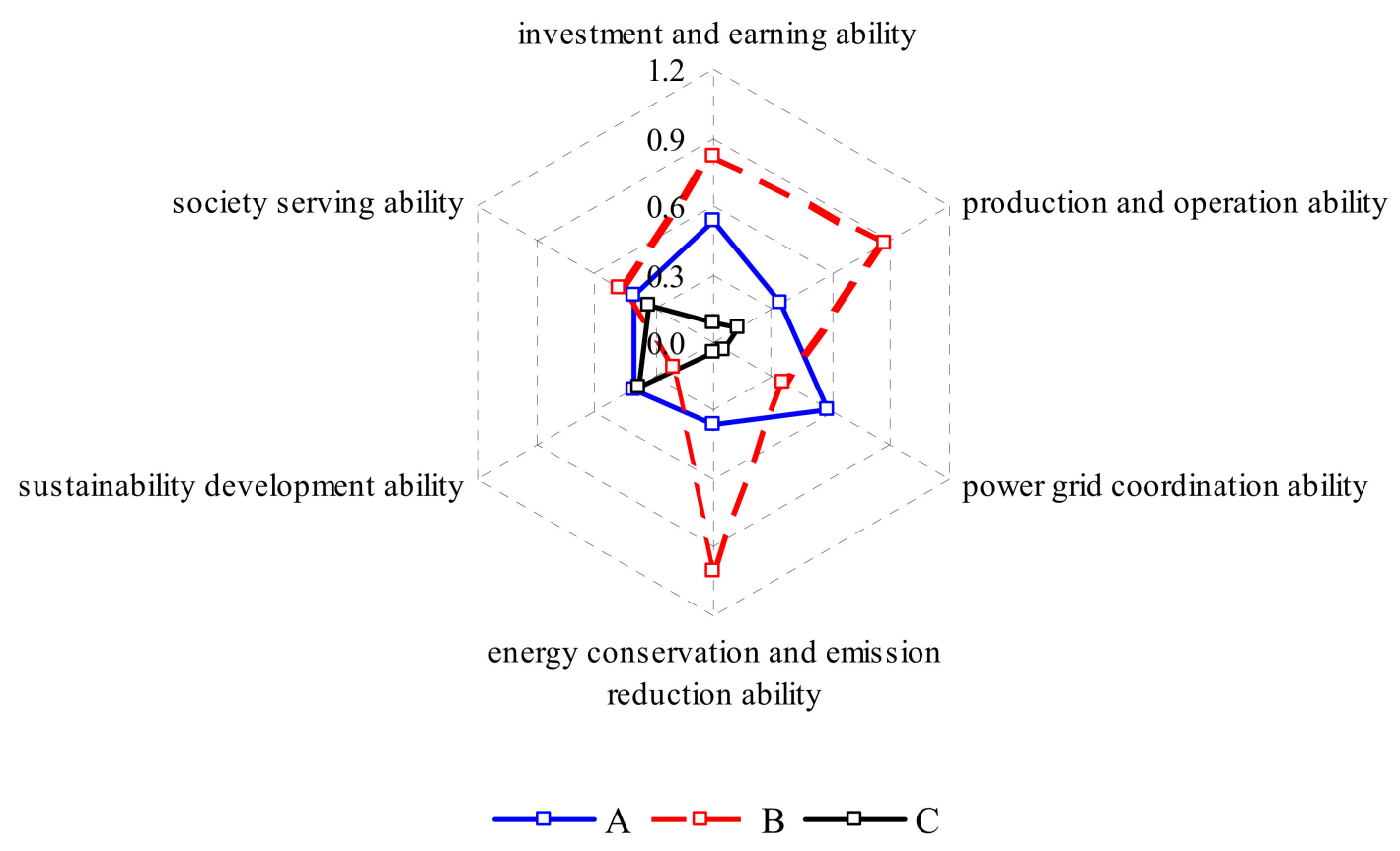

Figure 6. Core abilities evaluation results of each distributed PV project. 


\subsection{Validity Analysis}

In order to examine the evaluation effects and validity of the model proposed in this paper, an analytic hierarchy process (AHP) and a fuzzy comprehensive evaluation (FCE) were adopted to compare evaluation results with TOPSIS [37]. The comparison results are shown in Figure 7.

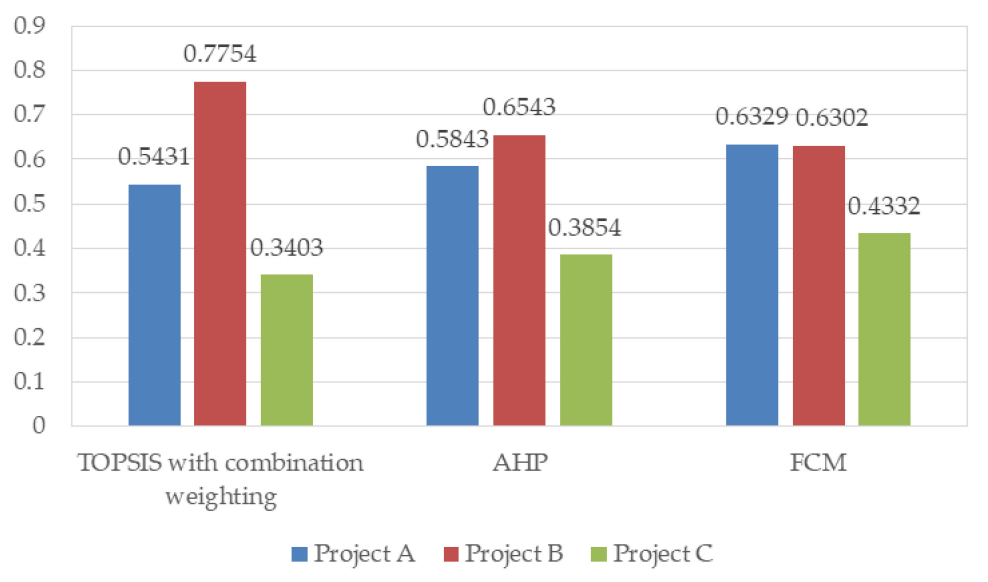

Figure 7. Evaluation result comparison of different methods.

From the comparison results in Figure 7, TOPSIS can highlight the evaluation differences in each project and take full advantage of original data. The TOPSIS evaluation results of projects A, B, C are 0.8754, 0.5431 and 0.2003 , respectively. However, through weighted average calculation, AHP has weakened the index values, which cannot focus on the evaluation characteristics in each project. In FCE evaluation, the results may be influenced mainly by some key indexes that cannot reflect the project features comprehensively. Thus, the improved TOPSIS method using combination weights can assess the core abilities of a distributed PV-generation project effectively. However, the model should be improved further through the examination of numerous project evaluations.

\subsection{Sensitivity Analysis}

Some indexes were chosen for the purpose of conducting a single-factor sensitivity analysis for the index weighting. The indexes are unit operation and maintenance cost $(0.0491)$, generation system efficiency (0.0492), annual amount of coal conservation (0.0450), and contributions to clean generation increment (0.0474) whose weighting values are bigger than 0.044 . With weight changes of $\pm 10 \%$, $\pm 20 \%$ and $\pm 40 \%$, the sensitivity analysis results of project B are shown in Figure 8 .

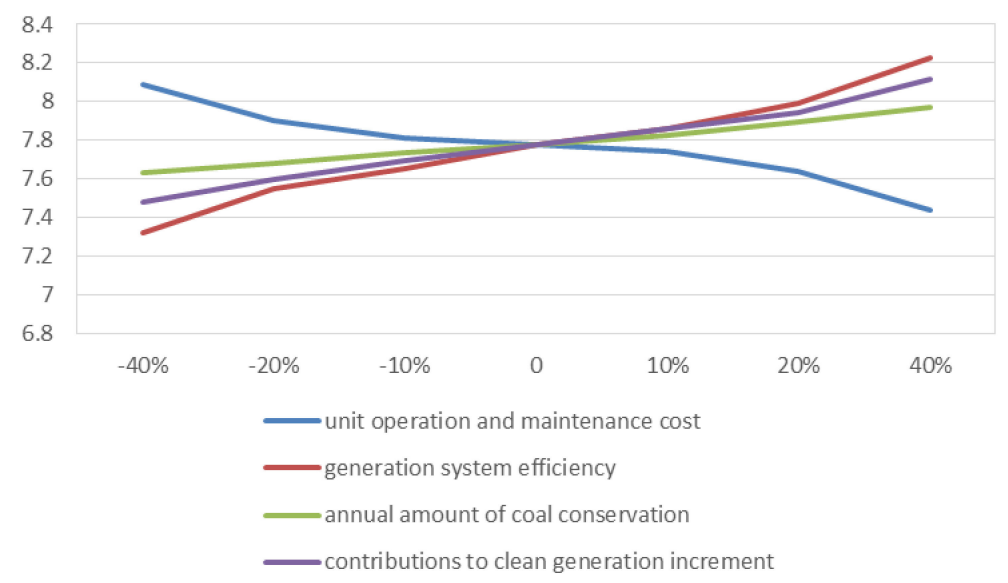

Figure 8. Sensitivity analysis results of index weighting on project B. 
From the results in Figure 8, we can find that the weighting of generation system efficiency has the most positive effect on the evaluation results, which are more sensitive than the weighting changes of annual amount of coal conservation and contributions to clean generation increment. On the other hand, the weight changing of unit operation and maintenance cost also has a negative impact on the evaluation results. This suggests that a greater focus needs to be placed on enhancing the generation system's efficiency and controlling the unit operation and maintenance cost in order to optimize the performance of distributed PV-generation project. On this developing stage, the government should play a crucial role in encouraging customers to use more distributed power and provide effective support for technology innovation and cost control.

\section{Conclusions}

Against the background of power market reform in China, distributed generation plays ever more important roles in electric power structure improvement, economic development pattern conversion, traditional energy saving and pollutant emission reduction. At the primary development stage of a distributed generation project, many challenging issues need to be improved and solved properly, such as the fierce competition between various generation types, the power grid's degree of acceptance of distributed power, and the production instability of distributed generation. Based on these problems, exploring the core abilities of distributed PV-generation projects may be meaningful and may help to promote their competitiveness. Therefore, identifying the factors or the indexes influential to the core abilities of distributed PV-generation projects should be determined from the outset. The factors affecting the core abilities of distributed PV-generation projects have been summarized by comprehensive methods of investigation, e.g., literature reviews, feasibility report analysis, and expert interviews. As the main contribution of this paper, the evaluation index system was established from 6 dimensions, i.e., investment and earning ability, production and operation ability, power grid coordination ability, energy-conservation and emission-reduction ability, sustainable development ability, and society-serving ability.

With this full-quantitative index system, the combination weighting method and TOPSIS evaluation model were adopted to reflect the data attributes. The combination weighting method can combine the advantages of both qualitative and quantitative weighting methods. Moreover, the TOPSIS evaluation model can fully use the data information from every indicator to make the evaluation results more accurate. On the basis of three practical projects, the weighting method and evaluation model were proved to be effective tools for assessing the core abilities of distributed PV-generation projects by comparison with the results of the AHP and FCE methods. From the evaluation results of core abilities, distributed PV-generation projects in different regions showed their shortcomings in each dimension of core abilities. For example, project B had better performances on the aspects of investment and earning ability, production and operation ability, and energy-conservation and emission-reduction ability. Project A showed more potential on power grid coordination ability and sustainable development ability, and project $C$ had a better society-serving ability. Meanwhile, validity and sensitivity analyses were also undertaken in the case studies. The relative methods can be used to select investment and construction plans and assess the competiveness of distributed PV-generation projects. This paper enriches the evaluation index system related to distributed generation projects, and also extends the application domains of TOPSIS with combination weights.

Additionally, highlighting the issues of abandoned power from centralized renewable power generation, distributed generation provides a possible approach to solving this problem. The analysis results can help managers and decision-makers to improve the core abilities of distributed PV-generation projects in order to promote the utilization efficiency of renewable power and realize sustainable and coordinated development. Positive policies and sound mechanisms are taking shape now in China. For example, in the 13th five-year energy development plan, China plans to construct $60 \mathrm{MW}$ of distributed PV-generation projects by the end of 2020. The 13th five-year solar energy development also proposed that the distributed PV projects should be developed preferentially. By the 
end of 2020, more than 100 demonstration zones of distributed PV application will be built. With greater popularization of distributed power generation systems, the proposed index system and evaluation method can also be employed for other issues, such as distributed wind power and distributed hydropower assessment. Its availability will also be improved through more practical studies.

Acknowledgments: This study is supported by the National Natural Science Foundation of China (NSFC) (71501071), the China Postdoctoral Science Foundation (2014M550937), the Ministry of Education in China Project of Humanities and Social Sciences (14JF005), the Beijing Social Science Fund (16YJC064), and the Fundamental Research Funds for the Central Universities.

Author Contributions: Li He and Chang-Ling Li proposed the concept of this research and completed the manuscript. Qing-Yun Nie, Yan Men and Hai Shao analyzed the empirical data. Jiang Zhu gave some suggestions.

Conflicts of Interest: The authors declare no conflict of interest.

\section{References}

1. National Bureau of Statistics of China. China's Electric Power Production Reviews in 2016. Available online: www.chinapower.com.cn (accessed on 11 May 2017).

2. National Energy Administration. Distributed PV Generation Capacity Has Increased 200\% in 2016. Available online: www.nea.gov.cn (accessed on 10 March 2017).

3. Comello, S.; Reichelstein, S. Cost competitiveness of residential solar PV, The impact of net metering restrictions. Renew. Sustain. Energy Rev. 2017, 75, 46-57. [CrossRef]

4. Carless, T.S.; Griffin, W.M.; Fischbeck, P.S. The environmental competitiveness of small modular reactors, a life cycle study. Energy 2016, 114, 84-99. [CrossRef]

5. Ziemele, J.; Pakere, I.; Blumberga, D. The future competitiveness of the non-Emissions Trading Scheme district heating systems in the Baltic States. Appl. Energy 2016, 162, 1579-1585. [CrossRef]

6. Feng, T.; Yang, Y.; Yang, Y.; Wang, D. Application status and problem investigation of distributed generation in China, The case of natural gas, solar and wind resources. Sustainability 2017, 9, 1022. [CrossRef]

7. Kadhem, A.A.; Wahab, N.I.A.; Aris, I.; Jasni, J.; Abdalla, A.N. Reliability assessment of power generation systems using intelligent search based on disparity theory. Energies 2017, 10, 343. [CrossRef]

8. Wu, Q.; Peng, C. Comprehensive benefit evaluation of the power distribution network planning project based on improved IAHP and multi-Level extension assessment method. Sustainability 2016, 8, 796. [CrossRef]

9. Min, C.; Kim, M. Flexibility-based evaluation of variable generation acceptability in Korean power system. Energies 2017, 10, 825. [CrossRef]

10. Escobar, R.A.; Cortés, C.; Pino, A.; Pereira, E.B.; Martins, F.R.; Cardemil, J.M. Solar energy resource assessment in Chile, Satellite estimation and ground station measurements. Renew. Energy 2014, 71, 324-332. [CrossRef]

11. Burnett, D.; Barbour, E.; Harrison, G.P. The UK solar energy resource and the impact of climate change. Renew. Energy 2014, 71, 333-343. [CrossRef]

12. Ramgolam, Y.K.; Soyjaudah, K.M.S. Unveiling the solar resource potential for photovoltaic applications in Mauritius. Renew. Energy 2015, 77, 94-100. [CrossRef]

13. He, G.; Kammen, D.M. Where, when and how much solar is available? A provincial-scale solar resource assessment for China. Renew. Energy 2016, 90, 38-45.

14. Al-Waeli, A.H.A.; Sopian, K.; Kazem, H.A.; Chaichan, M.T. Photovoltaic/Thermal (PV/T) systems, Status and future prospects. Renew. Sustain. Energy Rev. 2017, 77, 109-130. [CrossRef]

15. Jacobson, M.Z.; Delucchi, M.A. Providing all global energy with wind, water, and solar power, Part I, Technologies, energy resources, quantities and areas of infrastructure, and materials. Energy Policy 2011, 39, 1154-1169. [CrossRef]

16. Wang, H.; Zheng, S.; Zhang, Y.; Zhang, K. Analysis of the policy effects of downstream Feed-In Tariff on China's solar photovoltaic industry. Energy Policy 2016, 95, 479-488. [CrossRef]

17. Zhang, S. Innovative business models and financing mechanisms for distributed solar PV (DSPV) deployment in China. Energy Policy 2016, 95, 458-467. [CrossRef]

18. Park, A.; Lappas, P. Evaluating demand charge reduction for commercial-scale solar PV coupled with battery storage. Renew. Energy 2017, 108, 523-532. [CrossRef] 
19. Tomar, V.; Tiwari, G.N. Techno-economic evaluation of grid connected PV system for households with feed in tariff and time of day tariff regulation in New Delhi-A sustainable approach. Renew. Sustain. Energy Rev. 2017, 70, 822-835. [CrossRef]

20. Pillai, G.; Putrus, G.; Pearsall, N.; Georgitsioti, T. The effect of distribution network on the annual energy yield and economic performance of residential PV systems under high penetration. Renew. Energy 2017, 108, 144-155. [CrossRef]

21. Nookuea, W.; Campana, P.E.; Yan, J. Evaluation of solar PV and wind alternatives for self renewable energy supply: Case study of shrimp cultivation. Energy Procedia 2016, 88, 462-469. [CrossRef]

22. Flowers, M.E.; Smith, M.K.; Parsekian, A.W.; Boyuk, D.S.; McGrath, J.K.; Yates, L. Climate impacts on the cost of solar energy. Energy Policy 2016, 94, 264-273. [CrossRef]

23. Hanel, M.; Escobar, R. Influence of solar energy resource assessment uncertainty in the levelized electricity cost of concentrated solar power plants in Chile. Renew. Energy 2013, 49, 96-100. [CrossRef]

24. Ma, W.W.; Rasul, M.G.; Liu, G.; Li, M.; Tan, X.H. Climate change impacts on techno-economic performance of roof PV solar system in Australia. Renew. Energy 2016, 88, 430-438. [CrossRef]

25. Duan, H.; Zhang, G.; Zhu, L.; Fan, Y.; Wang, S. How will diffusion of PV solar contribute to China's emissions-peaking and climate responses? Renew. Sustain. Energy Rev. 2016, 53, 1076-1085. [CrossRef]

26. Yang, J.; Olsson, A.; Yan, J.; Chen, B. A Hybrid Life-cycle Assessment of CO2 Emissions of a PV Water Pumping System in China. Energy Procedia 2014, 61, 2871-2875. [CrossRef]

27. Kittner, N.; Gheewala, S.H.; Kammen, D.M. Energy return on investment (EROI) of mini-hydro and solar PV systems designed for a mini-grid. Renew. Energy 2016, 99, 410-419. [CrossRef]

28. Kumar, S.R.; Gafaro, F.; Daka, A.; Raturi, A. Modelling and analysis of grid integration for high shares of solar PV in small isolated systems-A case of Kiribati. Renew. Energy 2017, 108, 589-597. [CrossRef]

29. Zaid, S.A.; Kassem, A.M. Review, analysis and improving the utilization factor of a PV-grid connected system via HERIC transformerless approach. Renew. Sustain. Energy Rev. 2017, 73, 1061-1069. [CrossRef]

30. Lorenzi, G.; Silva, C.A.S. Comparing demand response and battery storage to optimize self-consumption in PV systems. Appl. Energy 2016, 180, 524-535. [CrossRef]

31. Calpa, M.; Castillo-Cagigal, M.; Matallanas, E.; Caamaño-Martín, E.; Gutiérrez, Á. Effects of large-scale PV self-consumption on the aggregated consumption. Procedia Comput. Sci. 2016, 83, 816-823. [CrossRef]

32. Franco, A.; Fantozzi, F. Experimental analysis of a self consumption strategy for residential building, the integration of PV system and geothermal heat pump. Renew. Energy 2016, 86, 1075-1085. [CrossRef]

33. Yamamoto, T.; Sakamoto, H. A new concept of Monte Carlo kinetics parameter calculation using complex-valued perturbation. Ann. Nucl. Energy 2014, 71, 480-488. [CrossRef]

34. Duan, Y.; Mu, H.; Li, N.; Li, L.; Xue, Z. Research on Comprehensive Evaluation of Low Carbon Economy Development Level Based on AHP-Entropy Method, A Case Study of Dalian. Energy Procedia 2016, 104, 468-474. [CrossRef]

35. Li, N.; Zhao, H. Performance evaluation of eco-industrial thermal power plants by using fuzzy GRA-VIKOR and combination weighting techniques. J. Clean. Prod. 2016, 135, 169-183. [CrossRef]

36. Mao, N.; Song, M.; Deng, S. Application of TOPSIS method in evaluating the effects of supply vane angle of a task/ambient air conditioning system on energy utilization and thermal comfort. Appl. Energy 2016, 180, 536-545. [CrossRef]

37. Zeng, F.; Cheng, X.; Guo, J.; Tao, L.; Chen, Z. Hybridising Human Judgment, AHP, Grey Theory, and Fuzzy Expert Systems for Candidate Well Selection in Fractured Reservoirs. Energies 2017, 10, 447. [CrossRef]

(C) 2017 by the authors. Licensee MDPI, Basel, Switzerland. This article is an open access article distributed under the terms and conditions of the Creative Commons Attribution (CC BY) license (http://creativecommons.org/licenses/by/4.0/). 